\title{
Efficacy of Three Light Technologies for Reducing Microbial Populations in Liquid Suspensions
}

\author{
Angeliki Birmpa, ${ }^{1}$ Apostolos Vantarakis, ${ }^{1}$ Spyros Paparrodopoulos, 1 \\ Paul Whyte, ${ }^{2}$ and James Lyng ${ }^{3}$ \\ ${ }^{1}$ Environmental Microbiology Unit, Department of Public Health, Medical School, University of Patras, Rio, 26500 Patras, Greece \\ ${ }^{2}$ School of Veterinary Medicine, University College Dublin, Belfield, Dublin 4, Ireland \\ ${ }^{3}$ School of Agriculture and Food Science, University College Dublin, Belfield, Dublin 4, Ireland \\ Correspondence should be addressed to Apostolos Vantarakis; avanta@upatras.gr
}

Received 29 November 2013; Accepted 24 January 2014; Published 4 March 2014

Academic Editor: Chrissanthy Papadopoulou

Copyright (C) 2014 Angeliki Birmpa et al. This is an open access article distributed under the Creative Commons Attribution License, which permits unrestricted use, distribution, and reproduction in any medium, provided the original work is properly cited.

\begin{abstract}
The aim of the current study was to evaluate the effectiveness of three nonthermal light technologies (NUV-Vis, continuous UV, and HILP) on their ability to inactivate Escherichia coli K12 and Listeria innocua. E. coli K12 was selected as a representative microorganism for the enterohaemorrhagic foodborne pathogen E. coli O157:H7 and L. innocua as a surrogate microorganism for the common foodborne pathogen Listeria monocytogenes, respectively. The liquid matrix used for the disinfection experiments was a liquid matrix (MRD solution). The results of the present study show that the HILP treatment inactivated both $E$. coli and $L$. innocua more rapidly and effectively than either continuous UV-C or NUV-vis treatment. With HILP at $2.5 \mathrm{~cm}$ from the lamp, $E$. coli and L. innocua populations were reduced by 3.07 and $3.77 \log _{10} \mathrm{CFU} / \mathrm{mL}$, respectively, after a $5 \mathrm{sec}$ treatment time, and were shown to be below the limit of detection $\left(<0.22 \log _{10} \mathrm{CFU} / \mathrm{mL}\right)$ following $30 \mathrm{sec}$ exposure to HILP $\left(106.2 \mathrm{~J} / \mathrm{cm}^{2}\right)$. These studies demonstrate the bactericidal efficacy of alternative nonthermal light technologies and their potential as decontamination strategies in the food industry.
\end{abstract}

\section{Introduction}

In recent years, nonthermal technologies have shown potential as alternatives to conventional pasteurization, with scope for inactivating pathogens and spoilage microorganisms without any of the adverse effects on product quality associated with thermal treatments such as reduced nutritional value or altered sensory attributes $[1,2]$.

Some pathogenic bacteria such as Listeria monocytogenes and other psychrotrophic bacteria can grow at low temperatures, threatening public health and shortening the shelf life of raw foods [3]. Many outbreaks associated with fresh readyto-eat produce have been reported previously with E. coli, Listeria, and Salmonella identified as implicated pathogens [3-8].

Currently fresh produce, fruit, and vegetables, are washed with aqueous sanitizers such as chlorine, hydrogen peroxide, and trisodium phosphate in order to reduce the microbial load of fresh produce. However, the use of aqueous sanitizers alone has not been successful in controlling foodborne pathogens [9] and treatment of produce with chlorine has adverse effects, such as formation of trihalomethanes [10,11]. Organic acids, mainly citric, lactic, and acetic acid, which are in GRAS (Generally Recognized As Safe) status, have been also used as disinfectants because of their bactericidal activity [12]. Hydrogen peroxide $\left(\mathrm{H}_{2} \mathrm{O}_{2}\right)$, also referred to as hydrogen dioxide, has also been used as bleaching agent due to its strong oxidizing power [12]. As a result there is a need for the development of additional effective hurdles for these raw foods which can eliminate or significantly reduce microbial contamination, be environmentally friendly while not impacting on the quality of foods [4]. A range of nonthermal technologies (Ultrasound, UV-C, Ozone, and HHP) have already been successfully implemented on a number of ready-to-eat fruits and vegetables [11, 13-17]. 
NUV-vis light $395 \pm 5 \mathrm{~nm}$ is a safe, non-UV based decontamination technology which is thought to act by stimulating endogenous microbial porphyrin molecules to produce oxidizing reactive oxygen species (ROS), predominantly singlet oxygen $\left({ }^{1} \mathrm{O}_{2}\right)$ that damages cells leading to microbial death [18-21]. Exposure of microorganisms to visible light particularly at wavelengths of $405 \mathrm{~nm}$, has been shown to be effective in inactivating a range of bacteria, including Gram- positive and Gram-negative bacterial species and antibiotic-resistant microorganisms such as Methicillin-resistant Staphylococcus aureus, and its use has been suggested for a range of decontamination applications [22-26].

The inactivation mechanism of UV light is the formation of photoproducts in the DNA of target microorganisms. Of these photoproducts, the most important is the pyrimidine dimer which forms between adjacent pyrimidine molecules on the same strand of DNA and can interrupt both DNA transcription and translation [27]. The DNA damage inflicted by UV-C radiation leads to cell death by altering the microbial DNA through dimer formation between neighbouring pyrimidine nucleoside bases in the same DNA strand [28, 29].

High-intensity light pulses (HILP) is a nonthermal technology which uses short (100-400 $\mu \mathrm{s})$ high-power pulses of broad-spectrum (200-1100 nm) and has been used to inactivate bacteria (vegetative cells and spores), yeasts, moulds, and even viruses $[30,31]$. The mode of action of HILP on microorganisms is likely the photochemical action of the UVC part of the light spectrum that causes thymine dimerization in the DNA chain preventing replication and ultimately leading to cell death [2,32-34]. Microbial inactivation using HILP has gained attention in recent years due to lower energy consumption compared to conventional thermal processes [35]. Depending on the energy delivered through each flash, the distance between the lamps and the contaminated matrix, the targeted microorganism, and even the nature of the contaminated matrix itself, HILP has been reported to result in a 0.5 to $8 \log _{10} \mathrm{CFU} / \mathrm{mL}$ bacterial reduction [36]. The germicidal action of HILP has been also attributed to the localized elevated temperature due to the UVs and IR radiations leading to bacterial disruption [33, 37-40].

The objective of the present work was to evaluate the effectiveness of three nonthermal light technologies (NUVvis, Continuous UV, and HILP) to reduce microbial populations in a liquid matrix. Different treatment intensities and times were selected in order to investigate the inactivation capacity of each light technology on one Gram-negative (E. coli $\mathrm{K}_{12}$ ) and one Gram- positive bacteria ( $L$. innocua NCTC 11288). E. coli K12 and L. innocua were selected as surrogate organisms for Escherichia coli O157:H7 and Listeria monocytogenes, respectively [2]. To the authors' knowledge, this is the first paper where all these three nonthermal light technologies were compared for their ability to inactivate possible foodborne pathogens.

\section{Material and Methods}

2.1. Microorganisms and Culture Preparation. Experiments were conducted using E. coli $\mathrm{K}_{12}$ (DSM 1607) and L. innocua
(NCTC 11288). The strains were maintained at $4^{\circ} \mathrm{C}$ on Tryptone Soya Agar, TSA (Oxoid, Hampshire, UK). For inoculation of the model solutions, cultures of $E$. coli or $L$. innocua grown overnight at $37^{\circ} \mathrm{C}$ in Tryptone Soya Broth, TSB (Oxoid), were used. The $24 \mathrm{~h}$ cultures were then centrifuged for $10 \mathrm{~min}$ at $30,000 \times \mathrm{g}$ and the resulting pellets were washed and centrifuged twice in Maximum Recovery Diluent (MRD, Oxoid) before being mixed together by resuspending in a final volume of $10 \mathrm{~mL}$ MRD. This resulted in mixed culture cell suspensions of $\sim 10^{8}$ colony forming units per milliliter (CFU/mL). The suspensions containing both $E$. coli and L. innocua inoculates were assessed for susceptibility to three light technologies in a liquid matrix (MRD). Mixed pure cultures (in MRD) were prepared as described previously. Samples $(10 \mathrm{~mL})$ were then placed into Petri dishes $(50 \mathrm{~mm}$ diameter). They were then positioned at different distances from the lamp source. After removal of covers, Petri dishes containing the MRD solutions were subjected to different light doses ranging from 0.18 to $106.2 \mathrm{~J} / \mathrm{cm}^{2}$.

\subsection{UV Equipment}

2.2.1. NUV-Vis Light Unit. The NUV-vis light was produced by a light-emitting diode (LED) array (OD-2049) (Opto Diode Corp, sourced from AP Technologies, Bath, UK) with a central wavelength of $395 \pm 5 \mathrm{~nm}$, a bandwidth of $12 \mathrm{~nm}$ full-width at half maximum (FWHM), and a half intensity beam angle of $30^{\circ}$ [40]. The irradiance $\left(\mathrm{J}^{2} \mathrm{~cm}^{-2}\right)$ of light emitted from the LED unit was measured using a UV-VIS Radiometer (model no. RM12, Dr. Gröbel UV Electronik, $\mathrm{GmbH}$, Ettlington, Germany) fitted with a RM UV-A sensor (part no. 811030, Dr. Gröbel UV Electronik). Distances of 3,12 , and $23 \mathrm{~cm}$ from the light source were chosen for treatments. The corresponding energy intensities and time needed to achieve them are presented in Table 1 . These distances represented the most extreme to the least extreme treatments according to the study of Haughton et al. [41]. Construction of the LED unit was as previously described [41]. Sample temperatures were measured during the treatment using a K-type thermocouple attached to a Grant Data Logger (Squirrel 2040; Grant Instruments) to ensure that the maximum temperature reached was nonlethal to the bacteria under the treatment times investigated $\left(<50^{\circ} \mathrm{C}\right)$ (Figure 6).

2.2.2. Continuous UV Equipment. The UV unit was a custommade unit with intimal dimensions (length $\times$ width $\times$ height) of $790 \times 390 \times 345 \mathrm{~mm}$ and consisting of four $95-\mathrm{W}$ bulbs (Baro Applied Technology Limited, Athens, Greece) $500 \mathrm{~mm}$ in length. The UV dose $(D)$ was calculated by using the following equation:

$$
D: I_{254 \mathrm{~nm}} * t,
$$

where $D$ is the dose $\left(\mathrm{J} / \mathrm{cm}^{2}\right), I_{254 \mathrm{~nm}}$ is the dosage rate, and $t$ is the retention time (in seconds). The UV dosages $\left(\mathrm{J} / \mathrm{cm}^{2}\right)$ were varied by altering the distance of the sample $(6.5,17$, and $28.5 \mathrm{~cm}$ ) from the light source and by changing the treatment time (Table 1). Sample temperatures were measured during the treatment using a K-type thermocouple attached to a 
TABle 1: Calculated exposure time (sec) of nonthermal light technologies at selected distances from the light source.

\begin{tabular}{|c|c|c|c|c|c|c|c|c|c|c|c|c|c|}
\hline & & & \multicolumn{11}{|c|}{ Dose per treatment $\left(\mathrm{J} / \mathrm{cm}^{2}\right)$} \\
\hline & & & 0.18 & 0.36 & 0.72 & 1.44 & 2.832 & 6 & 17.7 & 27 & 36 & 54 & 106.2 \\
\hline \multirow{10}{*}{$\begin{array}{l}\text { Distance from } \\
\text { light source } \\
(\mathrm{cm})\end{array}$} & 3 & \multirow{3}{*}{ NUV-VIS } & 6 & 11 & 22 & 45 & 88 & 186 & 548 & 836 & 1115 & * & * \\
\hline & 12 & & 28 & 55 & 110 & 221 & 435 & $*$ & $*$ & $*$ & $*$ & * & $*$ \\
\hline & 23 & & 149 & 298 & 595 & 1190 & 2341 & * & * & * & * & * & * \\
\hline & 6.5 & \multirow{3}{*}{ UV } & 30 & 60 & 120 & 240 & 472 & $*$ & * & * & * & $*$ & * \\
\hline & 17 & & 36 & 72 & 144 & 288 & 566 & * & * & * & * & * & * \\
\hline & 28.5 & & 45 & 90 & 180 & 360 & 708 & $*$ & $*$ & $*$ & * & $*$ & $*$ \\
\hline & 2.5 & \multirow{4}{*}{ HILP } & NT & NT & NT & NT & 0.8 & NT & 5 & NT & NT & NT & 30 \\
\hline & 8 & & 0.1 & 0.2 & 0.4 & 0.8 & NT & NT & NT & NT & NT & 30 & NT \\
\hline & 11.5 & & NT & 0.3 & 0.6 & NT & NT & 5 & NT & NT & 30 & NT & NT \\
\hline & 14 & & 0.2 & 0.4 & 0.8 & NT & NT & NT & NT & 30 & NT & NT & NT \\
\hline
\end{tabular}

NUV-Vis: near UV-vis light; UV: ultraviolet light; HILP: high-intensity light pulses.

(*) Samples that are not analyzed due to high temperature, NT: not tested samples. Distance from light source $(\mathrm{cm})$.

HILP was applied in pulses $360 \mu$ s duration at a frequency of $3 \mathrm{~Hz}$.

Grant Data Logger (Squirrel 2040; Grant Instruments) to ensure that the maximum temperature reached was nonlethal to the bacteria under the treatment times investigated $\left(<50^{\circ} \mathrm{C}\right)$ (Figure 7$)$.

2.2.3. HILP (High-Intensity Light Pulses) Unit. The HILP unit was a benchtop SteriPulse-XL system (Xenon, USA). The system comprised a high-energy pulsed ultraviolet-visible flash lamp (Type C, $190 \mathrm{~nm}$ spectral cut-off point) delivering a maximum of $1.27 \mathrm{~J} / \mathrm{cm}^{2}$. The pulse width produced was $360 \mu$ s at a fixed pulse rate of $3 \mathrm{~Hz}$. The pulse energy delivered to the sample varied depending on its distance from the quartz window within the HILP chamber. The HILP dose of treatments applied in the present study was calculated in accordance with the manufacturer's instructions [42]. Distances of $2.5,8,11.5$, and $14 \mathrm{~cm}$ were selected for treatments, in order to achieve a wide spectrum of dosages varying between 0.18 and $106.2 \mathrm{~J} / \mathrm{cm}^{2}$. The corresponding dosages and time needed to achieve them are presented in Table 1. During HILP treatment, samples were placed in an iced bath to minimize heating. Sample temperatures were measured during the treatment using a K-type thermocouple attached to a Grant Data Logger (Squirrel 2040; Grant Instruments, Cambridge, UK) to ensure that the maximum temperature reached was nonlethal to the bacteria under the treatment times investigated $\left(<50^{\circ} \mathrm{C}\right)$ (Figure 8$)$.

2.3. Microbiological Analysis. After treatment of liquid samples, the contents of each Petri dish were transferred to sterile containers. Tenfold dilution series were prepared in MRD and $0.1 \mathrm{~mL}$ of each dilution was pour plated in duplicate using TBX (CM0945, Oxoid) for E. coli and Listeria Selective Agar (Oxford formulation, CM0856, Oxoid) for $L$. innocua. The plates were incubated at $44^{\circ} \mathrm{C}$ and $37^{\circ} \mathrm{C}$ for 24 and $48 \mathrm{~h}$, respectively. Mean counts for each treatment were calculated and converted to $\log _{10} \mathrm{CFU} / \mathrm{mL}$ values with results for surviving numbers of microorganisms in MRD expressed per $\mathrm{mL}(\mathrm{CFU} / \mathrm{mL})$. The plates were then used to enumerate viable cells in untreated controls and in samples following processing. The survival of bacterial cells following illumination was monitored by counting their viable number after exposure of the suspended bacteria to light. Bacterial cultures grown under the same conditions but without light exposure served as controls. The results were expressed as the logarithmic reduction $\left(\log _{10} N / N_{0}\right)$, where $N_{0}$ is the initial microbial load and $N$ the number remaining after treatment. All experiments were repeated at least three times.

2.4. Statistical Analysis. All experiments were carried out in triplicate. During each experiment two samples were taken at any time to conduct microbial counts. The microbiological data were analyzed in terms of $\log _{10}\left(N / N_{0}\right)$, where $N$ is the microorganism load at a given time, and $N_{0}$ corresponds to the initial microbial load of untreated samples. The data for inactivation of E. coli and L. innocua by NUV-vis light, continuous UV and HILP were analyzed for statistical significance using SPSS 21.0 (SPSS Inc., Chicago, USA). Results were compared by an analysis of variance followed by Tukey's pairwise comparison of the means with significance defined at the $P<0.05$ level. Moreover, Pearson coefficient was used for measuring correlation between values.

\section{Results}

3.1. Inactivation Using NUV-Vis $395 \pm 5 \mathrm{~nm}$. The inactivation rate of E. coli and L. innocua was dose dependent. Generally, it was observed that as the distance from the lamp was increased, the time needed for inactivation was longer (Figure 1). Corresponding doses delivered by this method are illustrated in Table 1.

When low dosages were implemented $(0.18,0.36,0.72$, and $1.44 \mathrm{~J} / \mathrm{cm}^{2}$ ), the observed inactivation rates were similar 


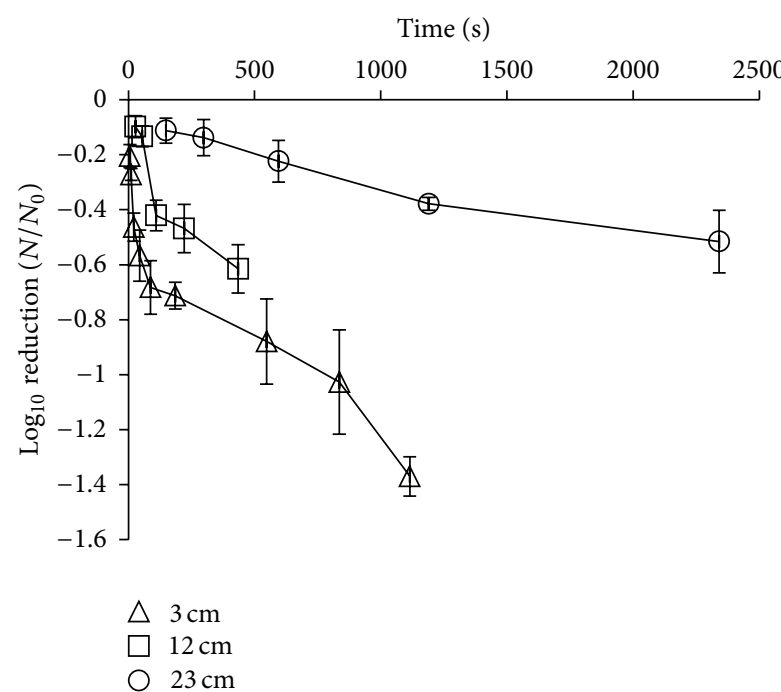

(a)

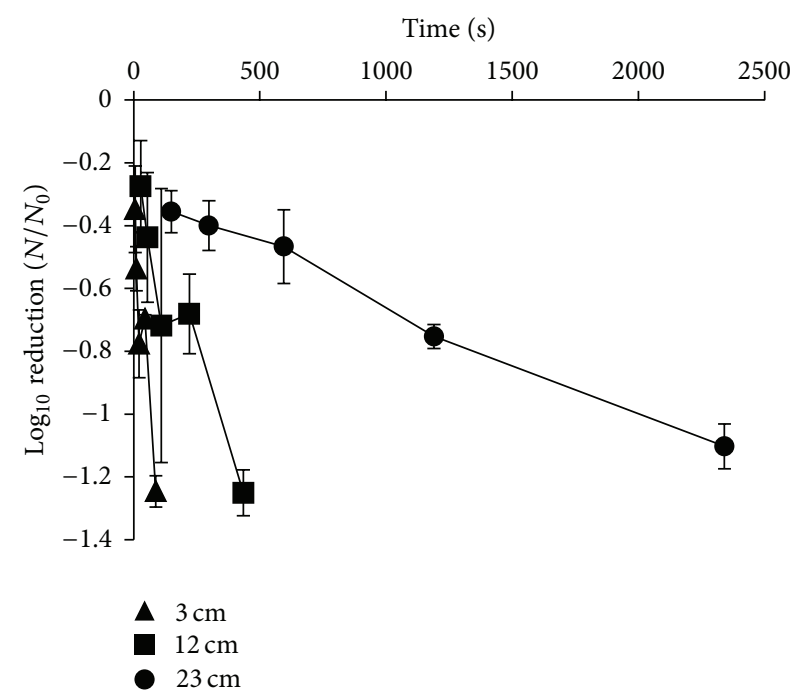

(b)

Figure 1: Survival curves of E. coli suspended in maximum recovery diluent (MRD) placed at $3 \mathrm{~cm}(\triangle), 12 \mathrm{~cm}(\square)$, and $23 \mathrm{~cm}(O)$ and $L$. innocua placed at $3 \mathrm{~cm}(\mathbf{\Delta}), 12 \mathrm{~cm}(\boldsymbol{\bullet})$, and $23 \mathrm{~cm}(\bullet)$ from the high-intensity near ultraviolet/visible (NUV-vis) $395 \pm 5 \mathrm{~nm}$ light source (results expressed as mean $\log _{10} \mathrm{CFU} / \mathrm{mL}$ ).

for both E. coli and L. innocua $(P>0.05)$. However, when a higher dose of $2.832 \mathrm{~J} / \mathrm{cm}^{2}$ was delivered, L. innocua exhibited a higher $\log$ reduction $\left(1.25 \log _{10} \mathrm{CFU} / \mathrm{mL}\right)$ compared to $E$. coli $\left(0.68 \log _{10} \mathrm{CFU} / \mathrm{mL}\right)$ after $88 \mathrm{sec}$ of treatment $(P<0.05)$, around 2 times the inactivation log of the more resistant bacterium of E. coli. Moreover, when high dosages were achieved, the inactivation rates of L. innocua remained significantly higher with a maximum average $\log _{10} \mathrm{CFU} / \mathrm{mL}$ reduction of 2.74 achieved after $1115 \mathrm{sec}$ of treatment, compared to that of E. coli where the maximum average log reduction after the same time was $1.37 \log _{10} \mathrm{CFU} / \mathrm{mL}(P<0.05)$. Moreover, the $\log$ reduction achieved for $L$. innocua remained higher than that of E. coli after the longest exposure time. At $23 \mathrm{~cm}$ from the light source, a higher susceptibility was observed for the L. innocua strain, giving a log reduction at the highest dose $\left(2.832 \mathrm{~J} / \mathrm{cm}^{2}\right)$ of $1.10 \log _{10} \mathrm{CFU} / \mathrm{mL}$, significantly greater $(P>0.05)$ than the corresponding reduction for $E$. coli (0.52 $\log _{10} \mathrm{CFU} / \mathrm{mL}$ reduction). It has to be mentioned that temperatures remained below $50^{\circ} \mathrm{C}$ for all treatments used in the study.

3.2. Inactivation Using Continuous UV Light. There was an increase between dosage and $\log _{10} \mathrm{CFU} / \mathrm{mL}$ reduction of both microorganisms. Reductions of $2.66 \log _{10} \mathrm{CFU} / \mathrm{mL}$ and $3.04 \log _{10} \mathrm{CFU} / \mathrm{mL}$ were achieved for E. coli and $L$. innocua, respectively. The highest reductions were achieved at the shortest distance from the lamp $(6.5 \mathrm{~cm})$ and at the shortest treatment time (472 sec) (Figure 2) when a dose of $2.832 \mathrm{~J} / \mathrm{cm}^{2}$ was implemented (Table 1). However, the susceptibility of two microorganisms when this light technology was used was not significantly different $(P=$ 0.749). Temperatures remained below $50^{\circ} \mathrm{C}$ for all treatments used in the study.
3.3. Inactivation Using HILP. The measured dosages delivered with this light method and the time needed to achieve them is illustrated in Table 1. In general, increased dosage resulted in the greater reductions for both $E$. coli and $L$. innocua. The least susceptible microorganism was E. coli (Figure 3). A dosage of $17.7 \mathrm{~J} / \mathrm{cm}^{2}$ resulted in $\log$ reductions of E. coli and L. innocua populations (3.07 and $3.77 \log _{10}$ $\mathrm{CFU} / \mathrm{mL}$, resp.) and were both below the limit of detection $\left(<0.22 \log _{10} \mathrm{CFU} / \mathrm{mL}\right)$ following exposure to HILP at $106.2 \mathrm{~J} / \mathrm{cm}^{2}$. When a dosage of $54 \mathrm{~J} / \mathrm{cm}^{2}$ was implemented, reductions of 4.81 and $5.56 \log _{10} \mathrm{CFU} / \mathrm{mL}$ were achieved for $E$. coli and L. innocua, respectively. At a dosage of $36 \mathrm{~J} / \mathrm{cm}^{2}$, a degree of variation was observed between the two tested microorganisms. For example, E. coli was reduced by $3.85 \log _{10} \mathrm{CFU} / \mathrm{mL}$, whereas $L$. innocua was reduced by $5.30 \log _{10} \mathrm{CFU} / \mathrm{mL}(P<0.05)$. The susceptibility of two microorganisms when this light technology was used was significantly different $(P<0.05)$. Temperatures did not exceed $50^{\circ} \mathrm{C}$ for any of the HILP treatments used in the current study.

3.4. Comparisons between Three Light Technologies. The three light technologies were tested for their disinfection capacity on two microorganisms (Figures 4 and 5). At low dosages $\left(0.18,0.36\right.$, and $\left.0.72 \mathrm{~J} / \mathrm{cm}^{2}\right)$ the results between the two microorganisms, when the three light technologies were used, were all significant $(P<0.05)$. When $1.44 \mathrm{~J} / \mathrm{cm}^{2}$ was implemented, the $\log _{10}(\mathrm{CFU} / \mathrm{mL})$ reduction at NUVvis light and continuous UV light for both microorganisms was significant $(P<0.05)$, whereas when comparisons with HILP light were done, the differences between the susceptibility of the tested microorganisms did not differ $(P>0.05)$. When $2.832 \mathrm{~J} / \mathrm{cm}^{2}$ was implemented in both 


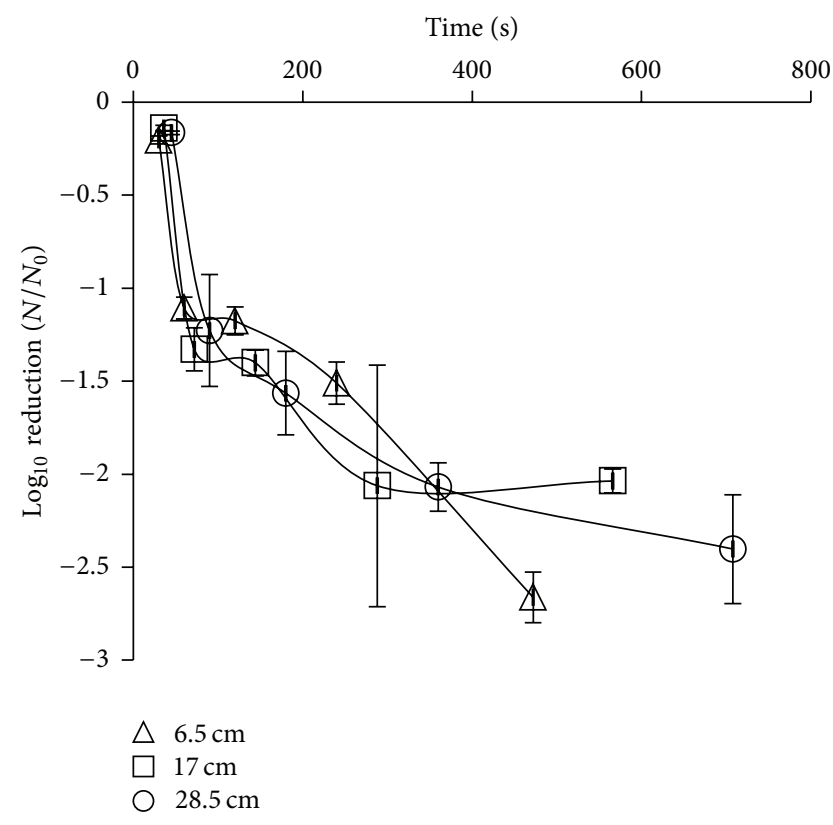

(a)

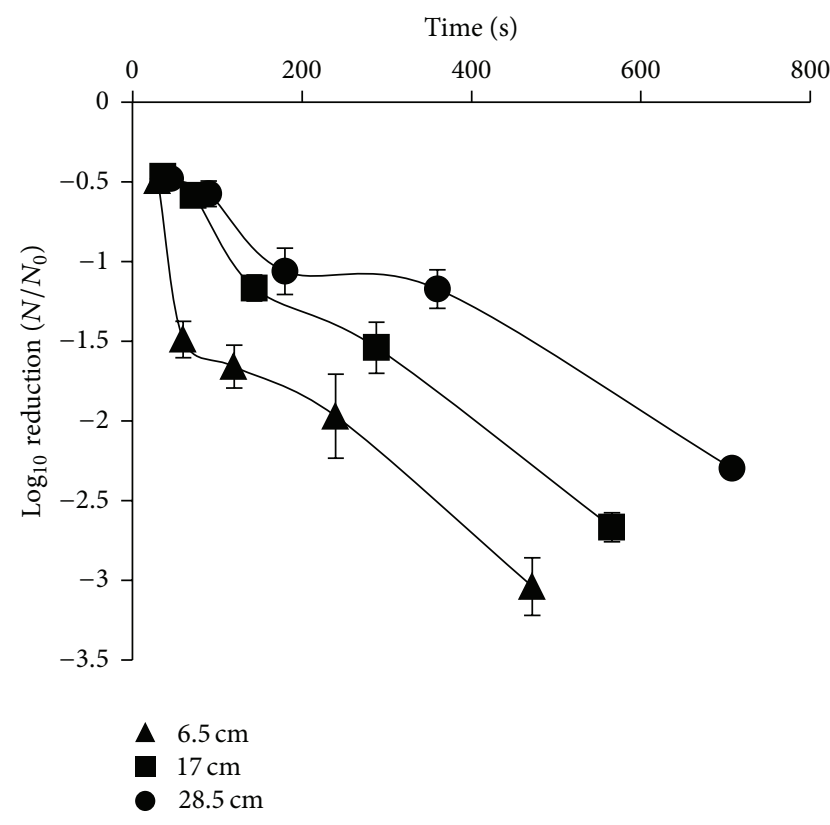

(b)

Figure 2: Survival curves of E. coli suspended in maximum recovery diluent (MRD) placed at $6.5 \mathrm{~cm}(\triangle), 17 \mathrm{~cm}(\square)$, and $28.5 \mathrm{~cm}(O)$ and $L$. innocua placed at $6.5 \mathrm{~cm}(\mathbf{\Delta}), 17 \mathrm{~cm}(\boldsymbol{\bullet})$, and $28.5 \mathrm{~cm}(\bullet)$ from continuous UV light source (results expressed as mean $\log _{10} \mathrm{CFU} / \mathrm{mL}$ ).

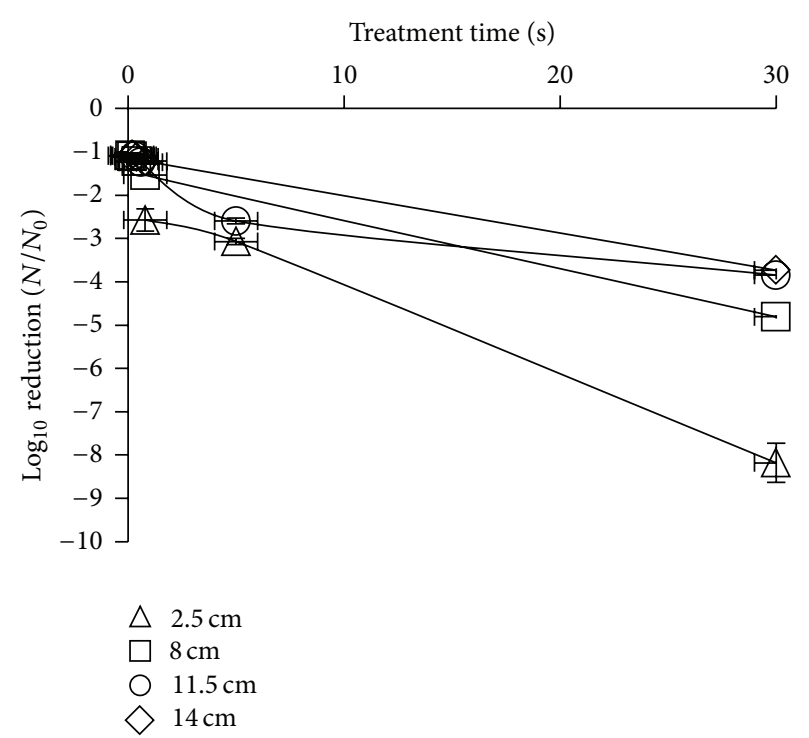

(a)

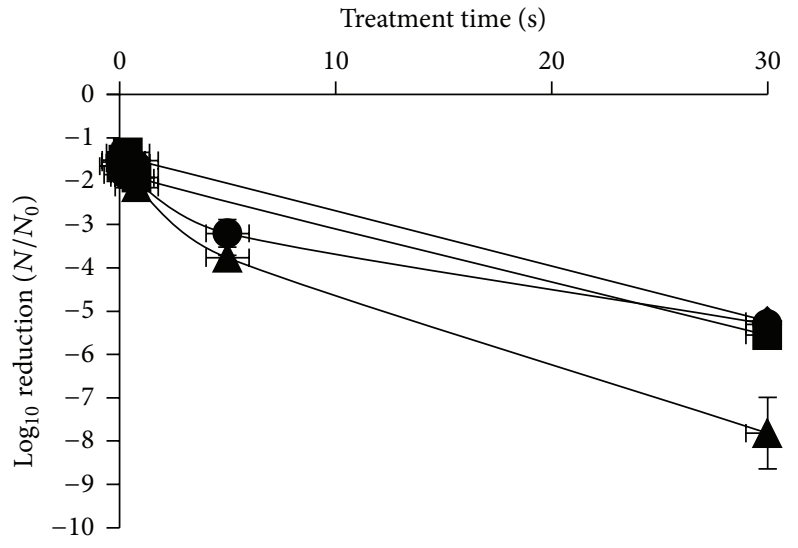

$2.5 \mathrm{~cm}$
$8 \mathrm{~cm}$

$11.5 \mathrm{~cm}$
$14 \mathrm{~cm}$

(b)

FiguRE 3: Survival curves of $E$. coli suspended in maximum recovery diluent (MRD) placed at $2.5 \mathrm{~cm}(\triangle), 8 \mathrm{~cm}(\square), 11.5 \mathrm{~cm}(O)$, and $14 \mathrm{~cm}$

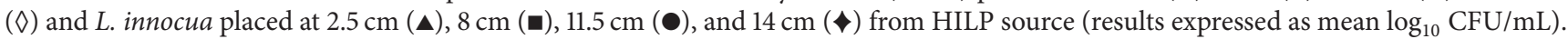

continuous UV light technology and HILP, the disinfection efficiency of $E$. coli and L. innocua did not differ significantly ( $P=0.306$ and $P=0.116$, resp.). Finally, at higher dosages, the correlations between $\log _{10}(\mathrm{CFU} / \mathrm{mL})$ reduction of NUVvis and PUV, as the two organisms are concerned, were all significant $(P<0.05)$. Generally, it was observed that in all light technologies (NUV-vis, continuous UV, and HILP) a significant correlation $(P<0.05)$ between doses and microbes $\log$ reduction existed (Figures 4 and 5).

\section{Discussion}

The current study demonstrated that both E. coli and $L$. innocua are susceptible to all three light technologies investigated. Previous studies have investigated the lethal effects of high-intensity ultraviolet $405 \mathrm{~nm}$ light on Escherichia, Salmonella, Shigella, Listeria, and mycobacteria as well as on Saccharomyces cerevisiae, Candida albicans, and spores of Aspergillus niger [21, 26]. In a study [43], the inactivation 


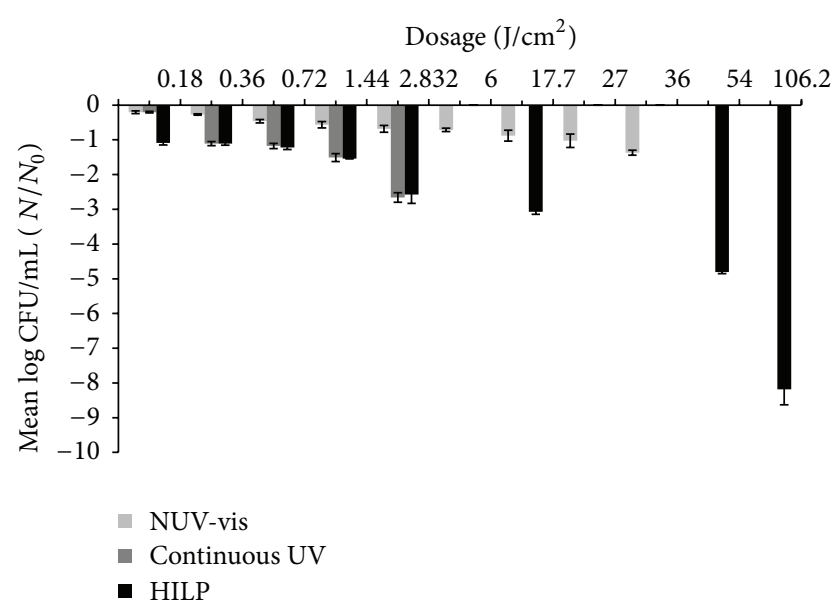

FIgUre 4: Mean $\log _{10} \mathrm{CFU} / \mathrm{mL}$ E. coli on MRD after treatment at the same dosages at shortest distance with 3 different light equipment.

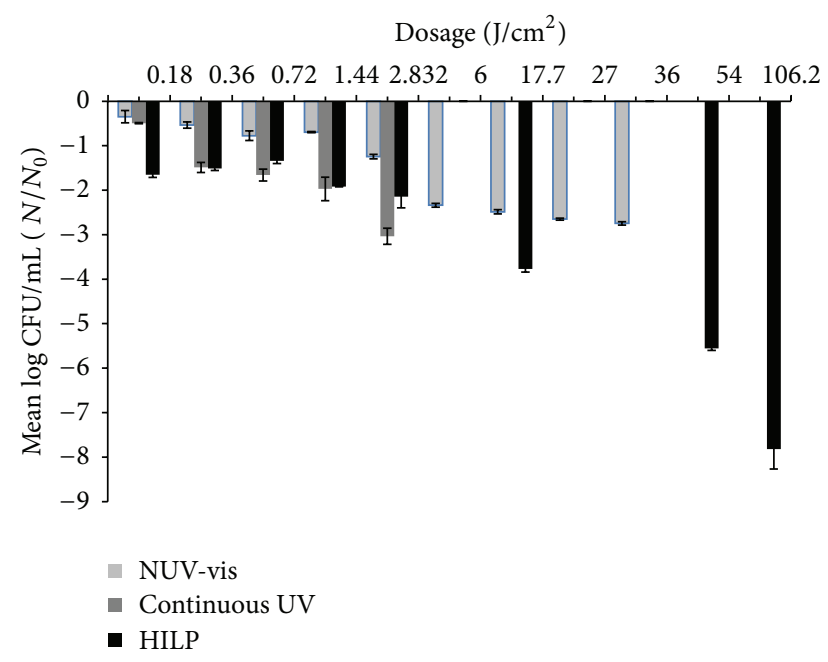

Figure 5: Mean $\log _{10}$ CFU/mL L. innocua on MRD after treatment at the same dosages at shortest distance with 3 different light equipment.

of E. coli and T4 and T7 phages after exposure to HILP was recorded. The evaluation of the effectiveness of HILP for the inactivation of $E$. coli and $L$. innocua in citric aciddisodium phosphate buffer solution was studied from Muñoz et al. [2]. However, the authors are unaware of any studies which directly compared the differences in susceptibility of E. coli and L. innocua to three different nonthermal light technologies (a NUV-vis light, a continuous UV, and a HILP light). So, the current study set out with two aims: (1) to test the relative susceptibility of two bacteria using three different light techniques; (2) to determine the effectiveness of each light equipment for inactivation of selected types of bacteria when different dosages are implemented.

Although longer treatment times resulted in significant temperature increases in all three light technologies, the dosages that were selected for this study did not result in temperature arise of more than $45^{\circ} \mathrm{C}$ (Figures 6, 7, and 8).

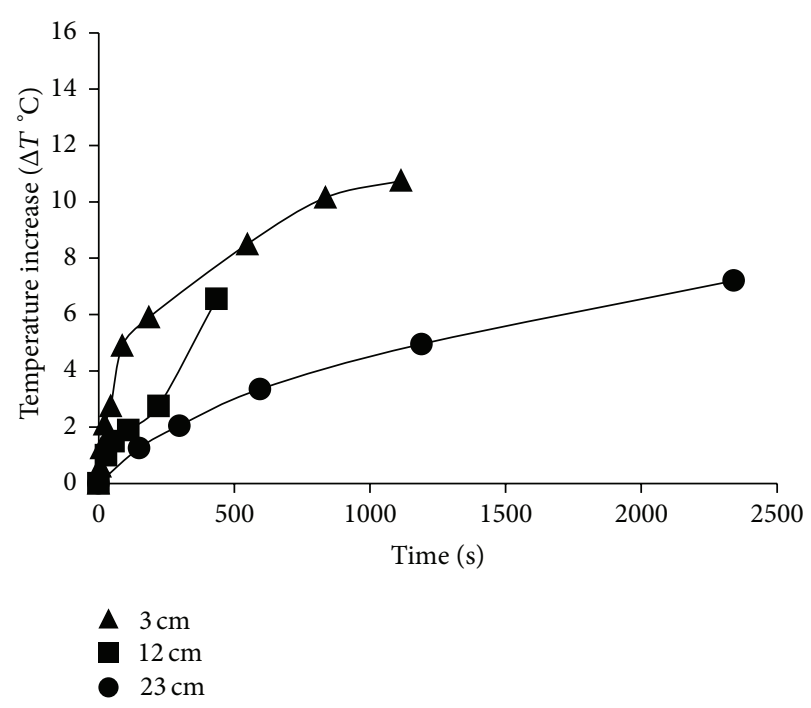

Figure 6: Mean Temperature increase $\left(\Delta T^{\circ} \mathrm{C}\right)$ for NUV-vis light technology at distances.

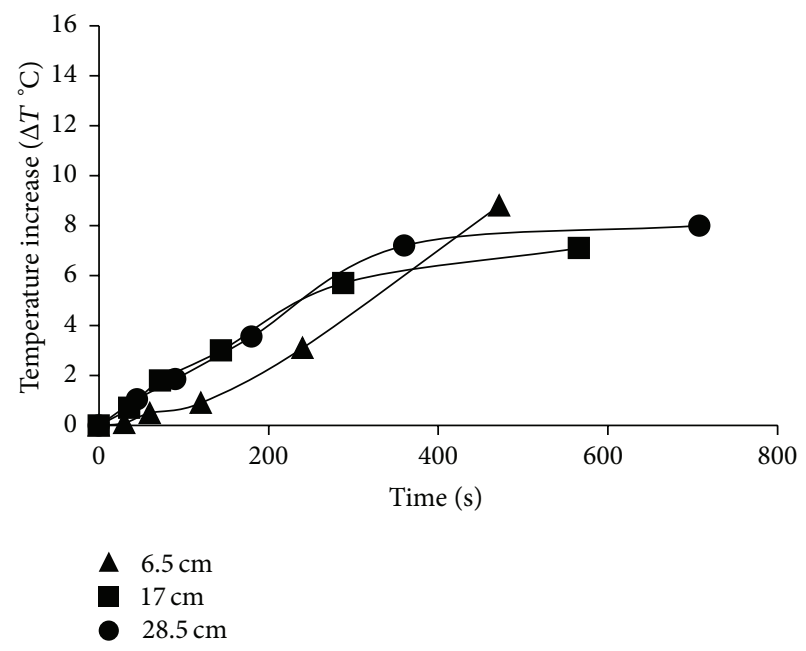

Figure 7: Mean Temperature increase $\left(\Delta T^{\circ} \mathrm{C}\right)$ for UV light technology at distances.

As the mechanism of inactivation by visible light is believed to be through the production of ROS, the susceptibility of both E. coli and L. innocua to ROS may play an important role in the inactivation of these organisms by NUV-vis light of $405 \mathrm{~nm}$ stimulates endogenous microbial porphyrin molecules to produce oxidizing reactive oxygen species (ROS), predominantly singlet oxygen $\left({ }_{1} \mathrm{O}^{2}\right)$ that damages cells leading to microbial death [20]. Specifically, $405 \mathrm{~nm}$ light has been shown to be capable of inactivating a range of predominantly nosocomial pathogens and also Gram-negative food-related pathogens [21,23].

When NUV-vis light was implemented, L. innocua proved to be the most readily inactivated organism compared to E. coli $(P<0.05)$. Murdoch et al. [21] found that L. monocytogenes was most readily inactivated in suspension, whereas S. enterica was most resistant. They concluded that $395 \pm 5 \mathrm{~nm}$ 


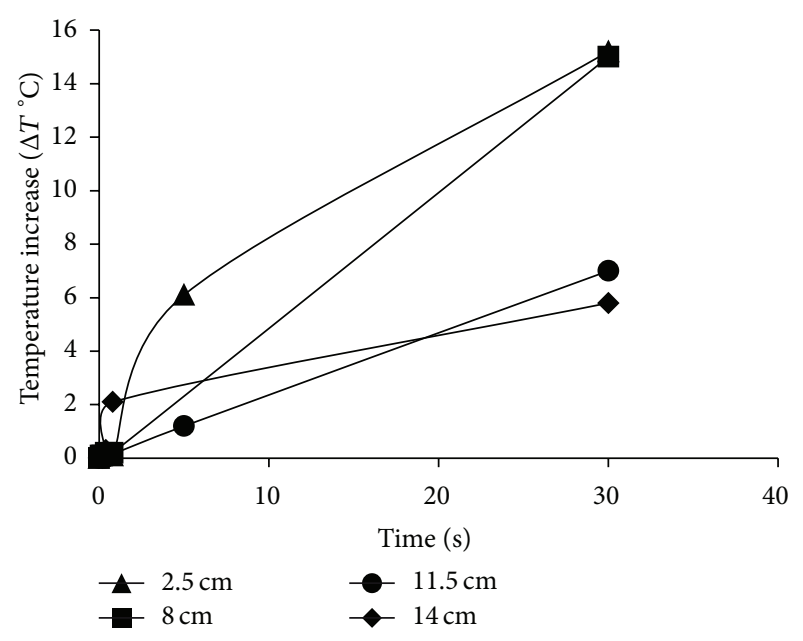

FIgURE 8: Mean Temperature increase $\left(\Delta T^{\circ} \mathrm{C}\right)$ for HILP light technology at distances.

light inactivates diverse types of bacteria in liquids and on surfaces, in addition to the safety advantages of this visible (non-UV wavelength) light [21]. In addition, it is reported [26] that fungal organisms may be somewhat more resistant to $405 \mathrm{~nm}$ light than bacteria. In this study a correlation between dose $\left(\mathrm{J} / \mathrm{cm}^{2}\right)$ and microbes' inactivation was found. Other studies have reported that Gram-positive species, in general, were more susceptible to $405 \mathrm{~nm}$ light inactivation than Gram-negative species, which is generally consistent with the results obtained in the current study [44]. The prokaryotic bacteria also exhibit considerable variability in susceptibility with values, to achieve $5-\log _{10}$ order reductions, as low as $18 \mathrm{~J} / \mathrm{cm}^{2}$ with Campylobacter jejuni [45] but most typically around $50-300 \mathrm{~J} / \mathrm{cm}^{2}$, with Gram-positive species being generally more susceptible than Gram-negatives [44]. Microbial inactivation by $405 \mathrm{~nm}$ light exposure has been found to be dose-dependent [21]. In applications where rapid inactivation is desirable, the use of a much higher power light source would significantly reduce the exposure times required for effective treatment. In our study, at the highest dosage $\left(36 \mathrm{~J} / \mathrm{cm}^{2}\right), 1.37 \log _{10} \mathrm{CFU} / \mathrm{mL}$ reduction was achieved for E. coli and a greater log reduction $\left(2.74 \log _{10}\right.$ $\mathrm{CFU} / \mathrm{mL}$ ) was achieved for L. innocua. Our results are in accordance with another study [21], where they found that $L$. monocytogenes was completely inactivated at an average dosage of $128 \mathrm{~J} / \mathrm{cm}^{2}$, whereas a $2.18 \log _{10}$ reduction was achieved for E. coli at $192 \mathrm{~J} / \mathrm{cm}^{2}$ dosage.

In the present study it was shown that, in order to achieve $2.66 \log _{10} \mathrm{CFU} / \mathrm{mL}$ reductions for E. coli and $3.04 \log _{10}$ $\mathrm{CFU} / \mathrm{mL}$ for $L$. innocua, respectively, a dosage of $2.832 \mathrm{~J} / \mathrm{cm}^{2}$ with continuous UV equipment was needed. However, the samples were not treated further due to the temperature arise. Our results are not in agreement with other studies [46] where better reductions $\left(7.2 \log _{10} \mathrm{CFU} / \mathrm{mL}\right.$ reduction and $4.6 \log _{10} \mathrm{CFU} / \mathrm{mL}$ reduction for E. coli and L. innocua, respectively, at $1.2 \mathrm{~kJ} / \mathrm{cm}^{2}$ ) were achieved, perhaps due to different $E$. coli and L. innocua strains that were used. UV light creates mutated bases that compromise cell functionality, but bacteria have developed DNA repair mechanisms to restore DNA structure and functionality [47]. This phenomenon is reflected in the shape of the inactivation curves of our experiment [48].

The killing effects of HILP are caused by the rich and broad-spectrum UV content, the short duration, and the high peak power of the pulsed light produced by the multiplication of the flash power manifold [32, 49]. Other researchers found that a significant reduction of $3.6 \log _{10} \mathrm{CFU} / \mathrm{mL}$ for $E$. coli $\mathrm{K}_{12}$ and $2.7 \log _{10} \mathrm{CFU} / \mathrm{mL}$ for L. innocua $(P<0.001)$ was achieved with HILP $\left(3.3 \mathrm{~J} / \mathrm{cm}^{2}\right)$ [2]. Our results are similar to that of study [2] as $2.57 \log _{10} \mathrm{CFU} / \mathrm{mL}$ reduction for $E$. coli and $2.14 \log _{10} \mathrm{CFU} / \mathrm{mL}$ reduction for L. innocua were achieved when $2.832 \mathrm{~J} / \mathrm{cm}^{2}$ dosage was implemented. To the best of the authors' knowledge three studies referring to the application of high-intensity light pulses in a continuous system $[42,50,51]$.

\section{Conclusions}

The results of the present study show that HILP treatments were more effective for the inactivation of both E. coli and L. innocua. Furthermore, this technology resulted in more rapid and extensive inactivation than either continuous UV$\mathrm{C}$ and NUV-vis treatments. These observations associated with HILP may be attributable to the comparatively higher penetration depth and emission power compared to continuous UV-C and NUV-vis. Moreover it has a high peak power produced by the multiplication of the flash power manifold, producing a light intensity at least 100 times greater than that of other two light technologies during the same operating time. However, research must be performed in real food matrixes, as it is known that HILP light generates off flavors. It can be concluded that short treatment times for decontamination efficiency would be an important factor related to productivity in food industry. The findings presented here suggest the expansion of the aforementioned light technologies on food decontamination. Thus these alternative nonthermal disinfection light techniques could find potential applications for decontamination in the food industry.

\section{Abbreviations \\ NUV-vis: Near ultraviolet/visible light \\ UV: Ultraviolet light \\ HILP: High-intensity light pulses \\ ROS: Reactive oxygen species \\ MRD: Maximum recovery diluent.}

\section{Conflict of Interests}

The authors declare that there is no conflict of interests regarding the publication of this paper. 


\section{References}

[1] J. Mosqueda-Melgar, R. M. Raybaudi-Massilia, and O. MartínBelloso, "Non-thermal pasteurization of fruit juices by combining high-intensity pulsed electric fields with natural antimicrobials," Innovative Food Science \& Emerging Technologies, vol. 9, no. 3, pp. 328-340, 2008.

[2] A. Muñoz, I. M. Caminiti, I. Palgan et al., "Effects on Escherichia coli inactivation and quality attributes in apple juice treated by combinations of pulsed light and thermosonication," Food Research International, vol. 45, no. 1, pp. 299-305, 2012.

[3] J. K. Andersen, R. Sorensen, and M. Glensbjerg, "Aspects of the epidemiological of Yersinia enterocolitica: a review," International Journal of Food Microbiology, vol. 13, no. 3, pp. 231-238, 1991.

[4] V. Ghate, K. S. Ng, W. Zhou et al., "Antibacterial effect of light emitting diodes of visible wavelengths on selected foodborne pathogens at different illumination temperatures," International Journal of Food Microbiology, vol. 166, pp. 399-406, 2013.

[5] L. R. Beuchat, "Pathogenic microorganisms associated with fresh produce," Journal of Food Protection, vol. 59, no. 2, pp. 204216, 1996.

[6] E.-J. Park, E. Alexander, G. A. Taylor, R. Costa, and D.-H. Kang, "Fate of foodborne pathogens on green onions and tomatoes by electrolysed water," Letters in Applied Microbiology, vol. 46, no. 5, pp. 519-525, 2008.

[7] B. Zhou, H. Feng, and Y. Luo, "Ultrasound enhanced sanitizer efficacy in reduction of Escherichia coli O157:H7 population on spinach leaves," Journal of Food Science, vol. 74, no. 6, pp. M308M313, 2009.

[8] CDC, "Centers for Disease Control and Prevention," Reports of Selected Outbreak Investigations, 2010, http://www.cdc .gov/foodsafety/outbreaks/multistate-outbreaks/outbreaks-list .html.

[9] B. A. Annous, G. M. Sapers, A. M. Mattrazzo, and D. C. R. Riordan, "Efficacy of washing with a commercial flatbed brush washer, using conventional and experimental washing agents, in reducing populations of Escherichia coli on artificially inoculated apples," Journal of Food Protection, vol. 64, no. 2, pp. 159$163,2001$.

[10] S. D. Richardson, A. D. Thruston Jr., T. V. Caughran, T. W. Collette, K. S. Patterson, and B. W. Lykins Jr., "Chemical byproducts of chlorine and alternative disinfectants," Food Technology, vol. 52, no. 4, pp. 58-61, 1998.

[11] H.-G. Sagong, S.-Y. Lee, P.-S. Chang et al., "Combined effect of ultrasound and organic acids to reduce Escherichia coli O157:H7, Salmonella Typhimurium, and Listeria monocytogenes on organic fresh lettuce," International Journal of Food Microbiology, vol. 145, no. 1, pp. 287-292, 2011.

[12] H. Ölmez and U. Kretzschmar, "Potential alternative disinfection methods for organic fresh-cut industry for minimizing water consumption and environmental impact," LWT-Food Science and Technology, vol. 42, no. 3, pp. 686-693, 2009.

[13] E. M. C. Alexandre, T. R. S. Brandão, and C. L. M. Silva, "Efficacy of non-thermal technologies and sanitizer solutions on microbial load reduction and quality retention of strawberries," Journal of Food Engineering, vol. 108, no. 3, pp. 417-426, 2012.

[14] A. Allende and F. Artés, "UV-C radiation as a novel technique for keeping quality of fresh processed "Lollo Rosso" lettuce," Food Research International, vol. 36, no. 7, pp. 739-746, 2003.

[15] D. Bermúdez-Aguirre and G. V. Barbosa-Cánovas, "Disinfection of selected vegetables under nonthermal treatments: chlorine, acid citric, ultraviolet light and ozone," Food Control, vol. 29, pp. 82-90, 2013.

[16] A. Birmpa, V. Sfika, and A. Vantarakis, "Ultraviolet light and ultrasound as non-thermal treatments for theinactivation of microorganisms in fresh ready-to-eat foods," International Journal of Food Microbiology, vol. 167, pp. 96-102, 2013.

[17] R. M. Syamaladevi, X. Lu, S. S. Sablani et al., "Inactivation of Escherichia coli population on fruit surfaces using ultraviolet-C light: influence on fruit surface characteristics," Food Bioprocess Technology, vol. 6, no. 11, pp. 2959-2973, 2013.

[18] M. Elman and J. Lebzelter, "Light therapy in the treatment of Acne vulgaris," Dermatologic Surgery, vol. 30, no. 2, pp. 139-146, 2004.

[19] O. Feuerstein, I. Ginsburg, E. Dayan, D. Veler, and E. I. Weiss, "Mechanism of visible light phototoxicity on Porphyromonas gingivalis and Fusobacterium nucleatum," Photochemistry and Photobiology, vol. 81, no. 5, pp. 1186-1189, 2005.

[20] M. Maclean, S. J. MacGregor, J. G. Anderson, and G. A. Woolsey, "The role of oxygen in the visible-light inactivation of Staphylococcus aureus," Journal of Photochemistry and Photobiology B, vol. 92, no. 3, pp. 180-184, 2008.

[21] L. E. Murdoch, M. Maclean, E. Endarko, S. J. MacGregor, and J. G. Anderson, "Bactericidal effects of $405 \mathrm{~nm}$ light exposure demonstrated by inactivation of Escherichia, Salmonella, Shigella, Listeria, and Mycobacterium species in liquid suspensions and on exposed surfaces," The Scientific World Journal, vol. 2012, Article ID 137805, 8 pages, 2012.

[22] T. Dai, A. Gupta, Y. Huang et al., "Blue light rescues mice from potentially fatal Pseudomonas aeruginosa burn infection: efficacy, safety, and mechanism of action," Antimicrobial Agents and Chemotherapy, vol. 57, pp. 1238-1245, 2013.

[23] C. S. Enwemeka, D. Williams, S. Hollosi, D. Yens, and S. K. Enwemeka, "Visible 405-nm SLD light photo-destroys methicillin-resistant Staphylococcus aureus (MRSA) in vitro," Lasers in Surgery and Medicine, vol. 40, no. 10, pp. 734-737, 2008.

[24] J. S. Guffey and J. Wilborn, "In vitro bactericidal effects of 405$\mathrm{nm}$ and 470-nm blue light," Photomedicine and Laser Surgery, vol. 24, no. 6, pp. 684-688, 2006.

[25] M. Maclean, S. J. MacGregor, J. G. Anderson et al., "Environmental decontamination of a hospital isolation room using high-intensity narrow-spectrum light," Journal of Hospital Infection, vol. 76, no. 3, pp. 247-251, 2010.

[26] L. E. Murdoch, K. McKenzie, M. Maclean, S. J. Macgregor, and J. G. K. Anderson, "Lethal effects of high-intensity violet 405$\mathrm{nm}$ light on Saccharomyces cerevisiae, Candida albicans, and on dormant and germinating spores of Aspergillus niger," Fungal Biology, vol. 117, pp. 519-527, 2013.

[27] C. M. A. P. Franz, I. Specht, G.-S. Cho, V. Graef, and M. R. Stahl, "UV-C-inactivation of microorganisms in naturally cloudy apple juice using novel inactivation equipment based on Dean vortex technology," Food Control, vol. 20, no. 12, pp. 11031107, 2009.

[28] T. Bintsis, E. Litopoulou-Tzanetaki, and R. K. Robinson, "Existing and potential applications of ultraviolet light in the food industry-a critical review," Journal of the Science of Food and Agriculture, vol. 80, pp. 637-645, 2000.

[29] B. R. Yaun, S. S. Sumner, J. D. Eifert, and J. E. Marcy, "Inhibition of pathogens on fresh produce by ultraviolet energy," International Journal of Food Microbiology, vol. 90, no. 1, pp. 1-8, 2004.

[30] D. Marquenie, A. H. Geeraerd, J. Lammertyn et al., "Combinations of pulsed white light and UV-C or mild heat treatment 
to inactivate conidia of Botrytis cinerea and Monilia fructigena," International Journal of Food Microbiology, vol. 85, no. 1-2, pp. 185-196, 2003.

[31] S. E. Woodling and C. I. Moraru, "Effect of spectral range in surface inactivation of Listeria innocua using broad-spectrum pulsed light," Journal of Food Protection, vol. 70, no. 4, pp. 909916, 2007.

[32] V. M. Gómez-López, P. Ragaert, J. Debevere, and F. Devlieghere, "Pulsed light for food decontamination: a review," Trends in Food Science and Technology, vol. 18, no. 9, pp. 464-473, 2007.

[33] I. Nicorescu, B. Nguyen, M. Moreau-Ferret, A. Agoulon, S. Chevalier, and N. Orange, "Pulsed light inactivation of Bacillus subtilis vegetative cells in suspensions and spices," Food Control, vol. 31, pp. 151-157, 2013.

[34] A. Rajkovic, N. Smigic, and F. Devlieghere, "Contemporary strategies in combating microbial contamination in food chain," International Journal of Food Microbiology, vol. 141, supplement, pp. S29-S42, 2010.

[35] G. V. Barbosa-Cánovas, M. M. Góngora-Nieto, and B. G. Swanson, "Non thermal electrical methods in food preservation," Food Science and Technology International, vol. 4, no. 5, pp. 363370,1998 .

[36] L. Hsu and C. I. Moraru, "Quantifying and mapping the spatial distribution of fluence inside a pulsed light treatment chamber and various liquid substrates," Journal of Food Engineering, vol. 103, no. 1, pp. 84-91, 2011.

[37] J. Dunn, "Pulsed-light treatment of food and packaging," Food Technology, vol. 49, no. 9, pp. 95-98, 1995.

[38] K. Takeshita, J. Shibato, T. Sameshima et al., "Damage of yeast cells induced by pulsed light irradiation," International Journal of Food Microbiology, vol. 85, no. 1-2, pp. 151-158, 2003.

[39] A. R. Uesugi and C. I. Moraru, "Reduction of Listeria on readyto-eat sausages after exposure to a combination of pulsed light and nisin," Journal of Food Protection, vol. 72, no. 2, pp. 347-353, 2009.

[40] A. Wekhof, "Disinfection with flash lamps," PDA Journal of Pharmaceutical Science and Technology, vol. 54, no. 3, pp. 264276, 2000.

[41] P. Haughton, E. Gomez Grau, J. Lyng, D. Cronin, S. Fanning, and P. Whyte, "Susceptibility of Campylobacter to high intensity near ultraviolet/visible $395 \pm 5 \mathrm{~nm}$ light and its effectiveness for the decontamination of raw chicken andcontact surfaces," International Journal of Food Microbiology, vol. 159, pp. 267-273, 2012.

[42] P. N. Haughton, J. G. Lyng, D. J. Morgan, D. A. Cronin, S. Fanning, and P. Whyte, "Efficacy of high-intensity pulsed light for the microbiological decontamination of chicken, associated packaging, and contact surfaces," Foodborne Pathogens and Disease, vol. 8, no. 1, pp. 109-117, 2011.

[43] Z. Bohrerova, H. Shemer, R. Lantis, C. A. Impellitteri, and K. G. Linden, "Comparative disinfection efficiency of pulsed and continuous-wave UV irradiation technologies," Water Research, vol. 42, no. 12, pp. 2975-2982, 2008.

[44] M. Maclean, S. J. MacGregor, J. G. Anderson, and G. Woolsey, "Inactivation of bacterial pathogens following exposure to light from a 405-nanometer light-emitting diode array," Applied and Environmental Microbiology, vol. 75, no. 7, pp. 1932-1937, 2009.

[45] L. E. Murdoch, M. MacLean, S. J. MacGregor, and J. G. Anderson, "Inactivation of Campylobacter jejuni by exposure to high-intensity 405-nm visible light," Foodborne Pathogens and Disease, vol. 7, no. 10, pp. 1211-1216, 2010.
[46] M. Schenk, S. Raffellini, S. Guerrero, G. A. Blanco, and S. M. Alzamora, "Inactivation of Escherichia coli, Listeria innocua and Saccharomyces cerevisiae by UV-C light: study of cell injury by flow cytometry," LWT-Food Science and Technology, vol. 44, no. 1, pp. 191-198, 2011.

[47] E. C. Friedberg, G. C. Walker, W. Siede, R. D. Wood, R. A. Schultz, and T. Ellenberger, DNA Repair and Mutagenesis, ASN Press, Washington, DC, USA, 2006.

[48] E. Gayán, I. Álvarez, and S. Condón, "Inactivation of bacterial spores by UV-C light," Innovative Food Science \& Emerging Technologies, vol. 19, pp. 140-145, 2013.

[49] C. I. Cheigh, H. J. Hwang, and M. S. Chung, "Intense pulsed light (IPL) and UV-C treatments for inactivating Listeria monocytogenes on solid medium and seafoods," Food Research International, vol. 54, pp. 745-752, 2013.

[50] K. Krishnamurthy, A. Demirci, and J. M. Irudayaraj, "Inactivation of Staphylococcus aureus in milk using flow-through pulsed UV-light treatment system," Journal of Food Science, vol. 72, no. 7, pp. M233-M239, 2007.

[51] H. H. Chun, J. Y. Kim, B. D. Lee, D. J. Yu, and K. B. Song, "Effect of UV-C irradiation on the inactivation of inoculated pathogens and quality of chicken breasts during storage," Food Control, vol. 21, no. 3, pp. 276-280, 2010. 

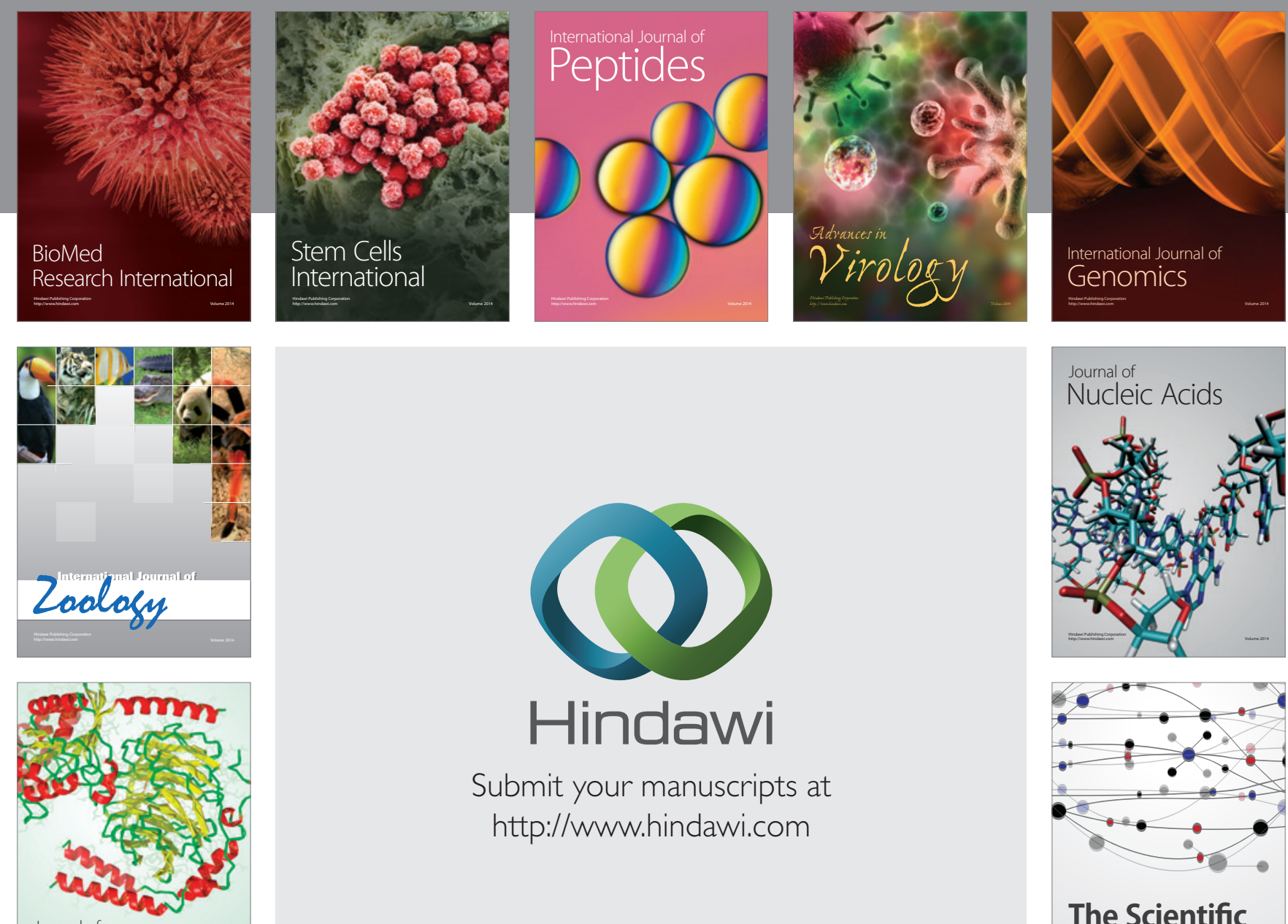

Submit your manuscripts at

http://www.hindawi.com

Journal of
Signal Transduction
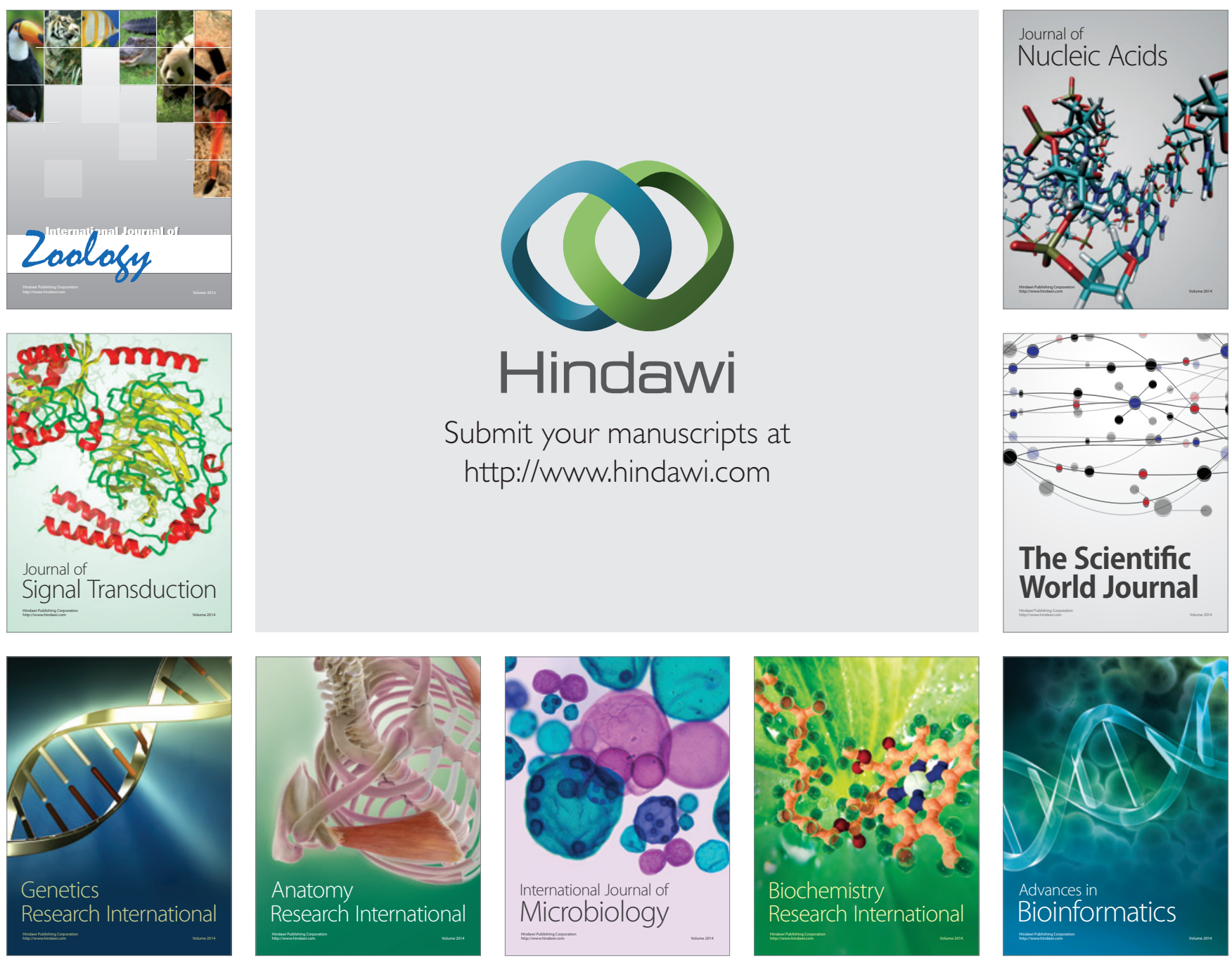

The Scientific World Journal
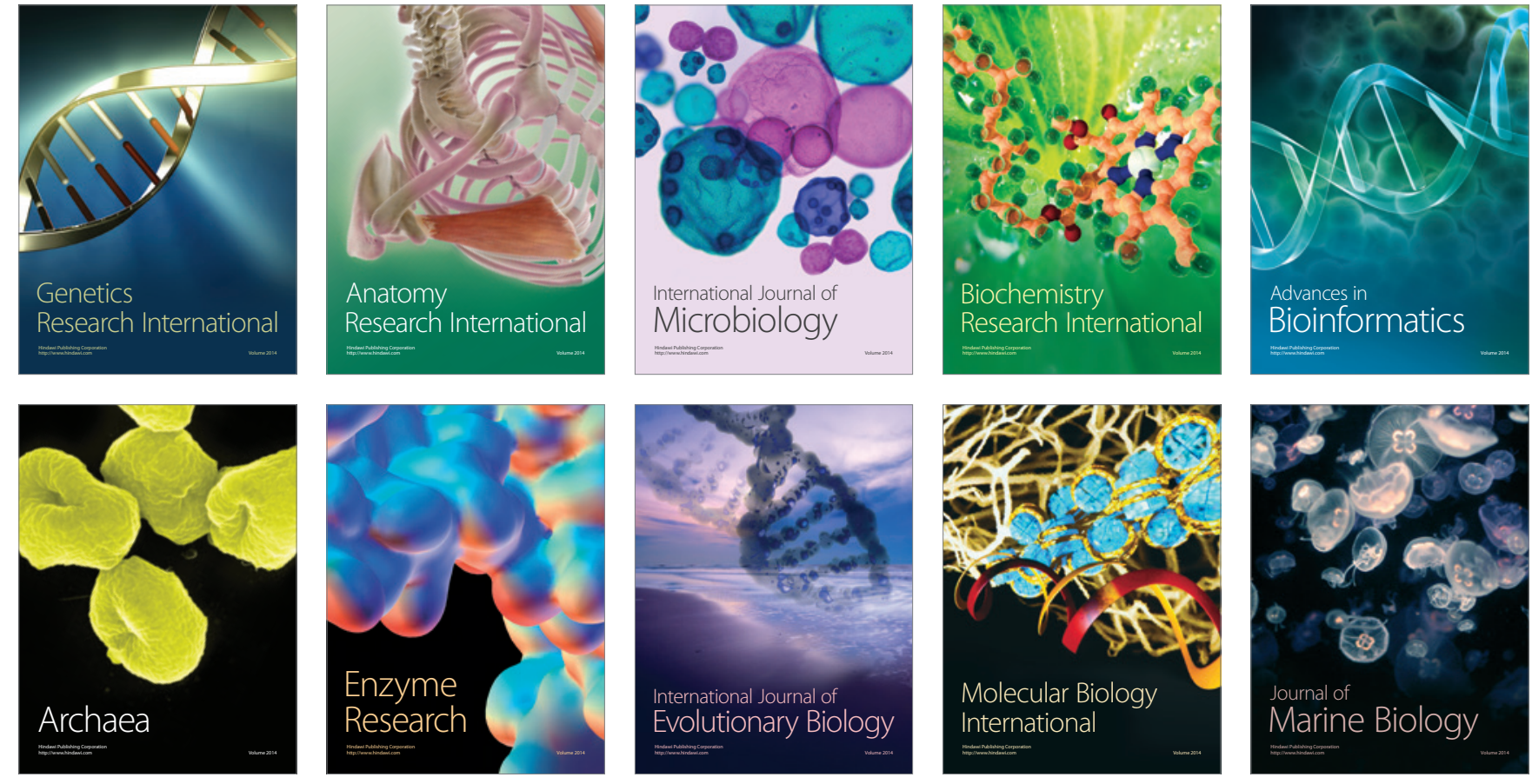